\title{
ARTICLE
}

\section{How Can Engineers Learn From The Past? A Potential Role for History in Engineering Education}

\author{
Andrea Gaynor ${ }^{*}$ and Greg Crebbin ${ }^{\dagger}$ \\ * History, Faculty of Arts, The University of Western Australia, andrea.gaynor@uwa.edu.au \\ † School of Engineering and IT, Murdoch University, g.crebbin@murdoch.edu.au
}

\begin{abstract}
At present, in many societies, engineers play a significant role in solving problems of energy, transport, accommodation and production; but similar problems have been solved through technical and nontechnical means for thousands of years. Numerous historical examples therefore exist, in which the ends of different approaches to problem-solving are apparent: some producing socially just and/or ecologically sustainable outcomes, and some less positive.
\end{abstract}

Historians do not simply narrate the past, they explain and interpret changes and continuities by paying attention to larger issues of, for example, class, gender, polity and economy. Such historical narratives, we argue, may have a useful role to play in efforts to shift the perspective of engineering students away from a narrow focus on complex technical solutions, towards the broader context in which their problem-solving will take place. This ability to assess the relationships between engineering problemsolving and the broader social and environmental context is critical to the development of a more sustainable and socially-just engineering practice.

KEYWORDS: history, engineering education

\section{INTRODUCTION}

Engineers play a significant role in shaping important dimensions of contemporary societies and environments. However, the dominant engineering paradigm in industrialised nations has been one of technical problem-solving, in which engineers were rarely required to consider the way a problem is framed (is it really a technical problem?), nor to work with social justice and ecological sustainability as key design criteria (Riley, 2008, pp. 40-1). ${ }^{1}$ A growing number of voices are advocating a new paradigm for engineering, with goals of sustainability and social justice at its core (Beder, 1998; Conlon, 2008; Johnston, McGregor, \& Taylor 2000). In this context we propose that the discipline of history could potentially be a valuable component of the education of "new engineers." Humanity has been solving problems through technical and non-technical means for thousands of years, and in recent years an increasing number of historical narratives have emerged in which the ends of different approaches to problem-solving are apparent: some producing outcomes that are socially and ecologically sustainable; others leading to disaster. Historians are well-placed to bring such episodes to life, engaging the imagination of engineering students as well

1 The story of the development of this paradigm in the Soviet Union is evocatively sketched out by Loren Graham (1993, chap. 4). 
as providing them with analyses that highlight the importance of engineers understanding the social and power relationships in which their work may intervene, as well as the ecological context.

\section{SUSTAINABILITY AND SOCIAL JUSTICE}

Before exploring this potential in greater detail, it is worthwhile reflecting in a general way on what we mean by sustainability and social justice, and the relationship between them. Social justice is a concept that resists a precise and stable definition, as our understanding of it always depends on our personal values and experiences. However, in a survey of how different organisations devoted to social justice conceive of it, Donna Riley (2008) has identified some common themes, namely "the struggle to end different kinds of oppression, to create economic equality, to uphold human rights or dignity, and to restore right relationships among all people and the environment" (p. 4). Here we see that the environment has a role to play in social justice, though the relationship between social justice and sustainability is contested, as is the concept of sustainability itself.

The idea of sustainable development, though far from novel, was popularised by the 1987 publication of Our Common Future, which summarised the work of the World Commission on Environment and Development (WCED). In it, sustainable development was defined as "development that meets the needs of the present without compromising the ability of future generations to meet their own needs" (World Commission on Environment and Development, 1987, p. 37). Much emphasis was subsequently placed on the notion of intergenerational equity, for example in the concepts of "strong" and "weak" sustainability. However, as Oluf Langhelle (2000) has pointed out, the fundamental goal of the WCED was to reconcile ecological sustainability with "need satisfaction, and equal opportunities within and between generations" (p. 297). Although the approach taken by the WCED has been criticised on a range of grounds (Irvine, 2003, p. 173), we argue that in principle, its effort to integrate issues of equity and environment was sound. Although some have proposed that there is no necessary connection between social justice and sustainability (Dobson, 2003), it seems clear to us that at a basic theoretical level, a just yet unsustainable society cannot survive, while an unjust yet sustainable society is not worth sustaining. Furthermore, there are often strong functional relationships between social equity and environment: for example, people living in poverty are likely to have fewer choices in relation to their environmental impacts, and often feel most acutely the effects of environmental degradation.

Therefore, we understand ecological sustainability and social justice as ideally integrated and identify them together throughout this paper in order to emphasise the way in which they are both critical to a more ethical engineering practice.

\section{THINKING HISTORICALLY/HISTORICAL THINKING}

What are the strengths of the discipline of history, and how may these be deployed to serve the transformation of engineering education? Historians do not simply construct lists of events or even just narrate the past, they explain and interpret changes and continuities by paying attention to broader contextual and structural elements, such as culture, political organisation, class, and gender.

How can we, living in the present, learn from historical studies? Despite a widespread popular belief in the need (and often failure) to "learn the lessons of the past," the context in which events occur is ever-changing, so history never repeats itself exactly. Its predictive potential is therefore limited: although it can tell us about potential preconditions to a particular outcome, and draw our attention to the characteristics of actors or contexts that shaped unfolding events, it cannot provide 
an infallible guide for contemporary behaviour. On the other hand, comparisons of the present and past can highlight which elements of our present circumstances are transient, and which are more enduring (Tosh, 2006, p. 34). This is one means by which it contributes to our store of knowledge about the present. History can also very usefully provide what John Tosh (2006) has called "an inventory of alternatives" (p. 32), and as cultural historian Natalie Zemon Davis (1984) has put it, "I show that things don't have to be the way they are now... I want to show that it could be different, that it was different, and that there are alternatives" (p. 114-115). This is not to say that historical narratives will provide comprehensive or even extensive descriptions of possible socially-just or ecologically-sustainable solutions to a particular "engineering" problem, not least as outcomes are far too contingent on particular historical contexts for that. Rather, their principal utility for engineering education lies in their ability to vividly demonstrate why understanding of the social and ecological contexts, as well as social justice and ecological sustainability as key outcomes, must form an intrinsic part of engineering practice. The past is littered with examples of the ruin precipitated by engineering practice lacking these features.

History is rarely singular, and if it is, it is rarely that way for long. Historical interpretations proliferate, diverge, and compete for followers. Hayden White (1973) has argued that histories are essentially stories, in which the interpretation presented has as much to do with rhetorical style and literary genre as it does any "truth" about the past. To put it another way, the past is not a story, but a history is. Although most historians retain a commitment to historical truth, they also recognise that history is not chronicle, and that in assembling facts into a narrative, issues of form (or rhetorical practice), as well as politics and preferences, come into play. In relation to the latter, William Cronon (1992) has proposed that:

Because stories concern the consequences of actions that are potentially valued in quite different ways, whether by agent, narrator, or audience, we can achieve no neutral objectivity in writing them. Historians may strive to be as fair as they can, but ... it remains possible to narrate the same evidence in radically different ways. (p. 1370)

Cronon (1992) then asks, how, in the face of divergent narratives, "are we to choose among the infinite stories that our different values seem capable of generating" (p. 1370). He proposes that the range of acceptable historical narratives is limited to those that "do not contradict known facts about the past," and that are produced within a critical community that demands respect for sources. Beyond that, the best "historical storytelling helps keep us morally engaged with the world by showing us how to care about it and its origins in ways we had not done before" (p. 1375). What this means for engineering educators seeking to draw on historical narratives in their classes is that they should choose the narratives most likely to inspire their particular group of students to approach problems by giving serious consideration to the social and ecological context, as well as whether the solution will deliver sustainable and socially-just outcomes.

Given that many historical narratives would not be in a form suitable for presentation to engineering students, and also because engineering faculty may not be very familiar with the relevant body of historical scholarship, it is likely that successfully introducing histories into engineering education would require at least some minimal collaboration between engineering educators and historians. Of course, the use of history alone will be unlikely to achieve a thoroughgoing commitment among engineering students to a sustainable and socially-just engineering practice. Rather, we anticipate that it would appear in the curriculum alongside complementary critical approaches and interventions, including perspectives from science and technology studies (Jasanoff, Markle, Peterson, \& Pinch, 2001; Jasanoff, 2004), appropriate design 
(Nieusma, 2004), and contemporary literature and case studies in engineering and social justice (Riley, 2008; Nieusma \& Riley, 2010).

One place within the curriculum with considerable potential for introducing historical narratives is the first engineering unit in an engineering degree program, which is often an introduction to the engineering profession that includes definitions of engineering and engineering processes, problem solving, communication skills, and issues of ethics, sustainability and social justice. This first unit may introduce engineering design and include a major design project, such as the Engineers Without Borders Challenge. ${ }^{2}$ For such projects, students need to identify social justice and sustainability issues as design objectives, as well as define metrics that measure whether these objectives have been achieved in the final design. Historical case studies might be used within this type of unit to encourage students to think broadly and critically about how to identify and work towards key community objectives, and to highlight-in a generic sense-the possible consequences of ignoring these objectives in their work process and final design. This might be accompanied by a discussion of some of the more specific issues involved in engineering and development projects. ${ }^{3}$ This first design project is typically a conceptual design task that is not discipline specific, and may in fact be multidisciplinary. In any case, historical examples that highlight the importance of addressing social issues in one engineering field should provide valuable lessons for any other engineering field. For example, with sufficient opportunity for discussion in which to tease out the relevant elements, the lessons learnt about the social and environmental impacts of gigantism in water management, which are directly relevant to civil and environmental engineers, could inform electrical engineers on the potential for similar long-term harm from gigantism in energy projects such as hydroelectric and geothermal energy generation.

In this article we outline, by way of example, two historical stories that might be used in an engineering education context to illustrate the divergent consequences of different approaches to the problem of irrigation, as engineered systems that divert, store and move water around a modified landscape for crop production purposes. Although employing similar engineering technology, in the form of canals, the two systems-in central Asia and the island of Bali-operated in different ecological settings, and perhaps even more importantly, in the context of different social and power relationships. As such, they led to very different social and ecological outcomes. These are of course only two of the many possible historical narratives that could be told of irrigation in the Aral basin and on Bali. The two we present both conform to historical facts and have been subject to critical scrutiny within an historical community, and were chosen with the aim of encouraging students to consider issues of scale, power, knowledge and proximity (as discussed below), as well as arriving at a general appreciation of the importance of context and the pursuit of just outcomes.

\section{EXAMPLE 1: THE ARAL SEA}

The Aral Sea is located in the deserts of central Asia, in the republics of Kazakhstan and Uzbekistan. It was once the world's fourth largest lake, but following a dramatic expansion of irrigated cotton production in its catchment, it now occupies less than ten percent of its original area (see Figure 1). This dramatic hydrogeological change, precipitated by the engineering of canals for large-scale irrigation schemes, has left a host of social and environmental problems in its wake.

${ }^{2}$ See http://www.ewb.org.au/whatwedo/institute/ewb-challenge.

${ }^{3}$ As outlined for example in Nieusma \& Riley (2010). 


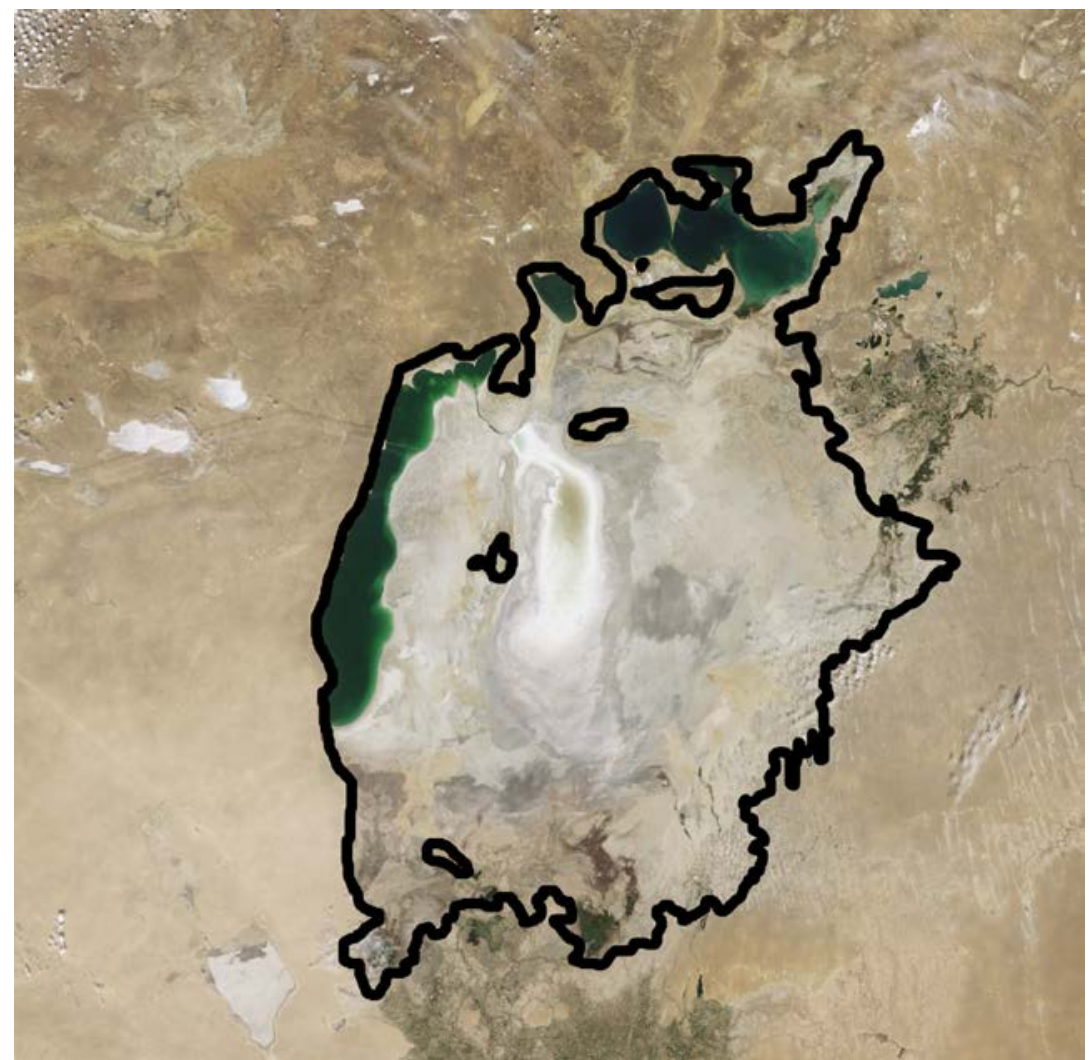

Figure 1. The Aral Sea, 2009, showing the approximate shoreline in 1960. Image courtesy of NASA Earth Observatory, http://earthobservatory.nasa.gov/IOTD/view.php?id=39944
The Aral basin has a very long history of irrigation, with irrigated orchards supporting wealthy settlements such as Bukhara and Urgench from the $9^{\text {th }}$ to $13^{\text {th }}$ centuries, until they were destroyed by the Mongols (Weiner, 2003, p. 70). For example, by the $12^{\text {th }}$ century the ancient city of Merv, in present-day Turkmenistan, had over 1 million inhabitants and a cultivated area of $700 \mathrm{~km}^{2}$ (O'Hara \& Hannan, 1999, p. 24). Despite using only a small part of the water of the Murgap river, the city was able to feed itself, and export food to adjacent areas. The writings of Arab historians and geographers reveal that at the heart of the system lay small plots that were intensively cultivated and watered regularly. The management of water was coordinated by a mirab, or water master, who was one of the most important people in the polity. Every canal was fitted with a water gauge and the level of the main canal was monitored hourly. The level of water flowing in spring guided decisions about how much land was to be cultivated each year, and in dry years only essential cultivation was undertaken. Around 12,000 people were employed in managing the system; water users contributed to the system through a water tax, and by assisting with annual maintenance activities, and construction of new works. This system operated effectively until the Mongol invasion, but was not re-established on the same scale thereafter, perhaps because of the level of centralised bureaucracy involved in its management.

In some areas, however, parts of the ancient systems of small-scale canals and irrigated farms survived through to the twentieth century. K. Sh. Sirozhidnikov has argued that in 1917, the year of the Russian Revolution, central Asia boasted a well-developed and environmentally-sustainable traditional irrigation system (Micklin, 1992, p. 270). Each farm was 2-3 hectares with irrigated fields of $0.3-0.8$ hectares, sufficiently small to be carefully managed. The fields were bounded by permanent low earthen walls, which prevented secondary salinisation by acting as salt accumulators. These walls were also planted with trees which transpired sufficient water to prevent waterlogging and drainage runoff. Irrigation was often undertaken at night, to minimise evaporation losses (O'Hara \& Hannan, 1999, p. 27). These systems were likely managed, as they were in neighbouring Afghanistan, by the villagers with the guidance of the village leaders or a nominated local mirab (Thomas \& Ahmad, 2009, p. 20; Weiner, 2003, p. 70). The system used basic equipment to withdraw water and canals were unlined, leading to water losses in the order of $30 \%$. In spite of this, because of the small scale and intensive management, the traditional system on 
average used less water per hectare than modern irrigation in the region, crop yields were higher, and fertility loss and soil salinisation were not serious problems, as they are today (Micklin, 1992, p. 270). In such systems, the landscape had been engineered to produce crops in a desert, but the engineering was small-scale, locally_and carefully_managed, and apparently sustainable.

However, such systems would soon be radically transformed. As Central Asia was annexed by the Russian Empire in the late $19^{\text {th }}$ century, engineers and agricultural experts were sent to the region. After seeing the existing irrigation, and the remains of the larger systems not resurrected after the Mongol invasion, they reported that it had significant potential for irrigated cotton production, and drew up plans for large-scale schemes. These failed to find financial backers, so were not implemented under the Tsarist regime (O'Hara \& Hannan, 1999, p. 25). In 1920, however, Lenin declared that irrigation in central Asia would be modernised; the destruction of traditional irrigation systems was accelerated with the creation of large collective and state farms under Joseph Stalin from the 1930s (Weiner, 2003, p. 70; Micklin, 1992, p. 270). The acreage under irrigated cotton increased, and that devoted to food production declined. By this time, the political climate in the Soviet Union was such that engineers had become justifiably afraid of speaking out about social and economic problems associated with engineering projects: at least one engineer critical of Soviet engineering practice was executed. Furthermore, the education of engineers in the Soviet Union had become increasingly narrow and technical, with an exclusive focus on increasing production (Graham, 1993, p. 68). Informed dissent from engineers was thereby extinguished.

In the 1950s, under Soviet Premier Khrushchev, there was a dramatic expansion in the area earmarked for the production of irrigated cotton in the region. At that time, most irrigation was drawn from the smaller rivers as the largest, the Amu Dar'ya and Syr Dar'ya, presented considerable challenges to irrigation engineers, being fast-flowing rivers with high banks, strong currents, fluctuating levels and changing courses (Lewis, 1962, p. 103). However, Soviet engineers rose to the challenge, designing more complex diversion and storage facilities, and larger and longer canals. By these means, it was anticipated the water from the two major rivers feeding the Aral Sea would make the desert bloom and the Soviets self-sufficient in cotton. Construction of the largest canal, the Karakum, commenced in 1954. By 1999 it diverted almost $13 \mathrm{~km}^{3}$ of water along its length, and irrigated around 1 million hectares of land (O'Hara \& Hannan, 1999, p. 25). Not only did the area of irrigated land increase, but also the use of water per hectare. Large-scale works like the Karakum canal created an illusion of an almost limitless water supply; furthermore, it was essentially free, and there was relatively little monitoring equipment. In combination, these factors led to endemic over-watering, leading to local problems of waterlogging and secondary salinisation (O'Hara \& Hannan, 1999, p. 27). That measures to avoid this outcome were not made an integral part of the system is surprising given that even in 1953 it was known that soil salinity was a major problem in the area: at that time, for example, $88 \%$ of the irrigated land in the Turkmen S. S. R. was classified as saline (Lewis, 1962, p. 106).

In 1960 the total river run-off into the Aral Sea was $40 \mathrm{~km}^{3}$; by 1975 this had fallen to just $11 \mathrm{~km}^{3}$; in 1980 there was no significant runoff at all, and the sea level had fallen by 7 metres (Kotlyakov, 1991, p. 6). By that time, crop yields were also beginning to decline (Brookfield, 1999, p. 6). The increasing quantities of water extracted by the system were rapidly beginning to threaten the area's ecological and economic foundations. The threat to the Aral Sea from the irrigation expansion was not unforeseen. In 1968 Soviet scientist V. L. Shul'ts declared that "it is necessary to drain the Aral Sea in the future... The time has come for the rational use of the water resources of the Aral basin for the benefit of the Soviet people building communism" (Glantz, Rubinstein, \& Zonn, 1993, p. 187). It was often argued at the time that the monetary return from water used for irrigation would be greater than if the same water were allowed to run to the sea, even if that ultimately 
meant the loss of the Aral Sea. Dissenting voices were ignored in the single-minded pursuit of the policy of rapid expansion of cotton production, in which Soviet engineers were apparently-and understandably—compliant participants (Glantz et al., 1993, p. 188). ${ }^{4}$

In the 1960s and 70s, the consequences of the over-developed and under-managed irrigation system in the Aral basin began to be noted in the scientific literature. They included:

wind erosion, salt-laden dust storms, destroyed spawning grounds, the collapse of the fisheries, secondary salinization, increased salinity of seawater, waterlogging, disruption of navigation, the likely division of the sea into separate parts, the need for extra-basin water resources to stabilize the sea level, the loss of wildlife in the littoral areas, the large reduction of streamflow from the two main tributaries, a change in the regional climate, the disappearance of pasturelands, and so on. (Glantz et al., 1993, p. 189)

By the 1970s, over 46,000 hectares of degraded land were being abandoned in Turkmenistan alone every year (O'Hara \& Hannan, 1999, p. 27). The previously productive fishery ceased in 1985 (Brookfield, 1999, p. 6). The erosion of the resource base of much local economic activity has led to considerable unemployment and consequent poverty in the region. The cost in terms of human health has also been enormous, as the toxic pesticides used in cotton production have accumulated in areas that are now desiccated, and are blown on dusty winds into towns and homes. Pollution of air and water, lack of potable water, and lack of appropriate food has precipitated a public health crisis, with extremely high infant and maternal mortality rates, widespread illness, and reduced life expectancy (Glantz et al., 1993, p. 185; Kotlyakov, 1991, p. 8). Ecosystem effects have also been devastating. By 1991, just over half of the bird species previously found, and just under half of the mammal species, remained in the region (Kotlyakov, 1991, p. 7). As irrigation has continued, and the sea has continued to shrink, these problems have continued and in some cases increased.

\section{EXAMPLE 2: BALI}

Historical examples of more socially just and ecologically sustainable engineering are, unfortunately, few and far between. However, one such example may be found in another highlyengineered irrigation landscape, Bali. Much of the historical work on Bali comes to us from sociocultural anthropologists, intent on explaining a system of social organisation that Clifford Geertz referred to as "pluralistic collectivism" (Geertz \& Geertz, 1975, p. 30). This is characterised by multiple power structures, with individuals involved in several different groups, each of which has a particular single purpose. For hundreds of years, the complex irrigation systems that produce much of the Balinese people's food have been managed at a local level by one such set of groups, known as subaks. Subaks are irrigation societies, each consisting of between 50 and 400 farmers, who draw water for irrigation from a common source such as a dam, spring, or irrigation channel. Subak leaders are elected by members, who meet regularly to plan cropping and maintenance tasks, and allocate water on an equitable basis. A series of higher-order water temples link subaks using a common water source, such as a river or main canal; for at least half of the island, this hierarchy terminates at what is believed to be the ultimate source of the island's fresh water, the Temple of the Crater Lake (Schoenfelder, 2000, p. 38). Today, a subak is "a semiautonomous sociopolitical and socioeconomic unit responsible for group decision-making about the irrigated landscape" (Scarborough, Schoenfelder, \& Lansing, 2000, p. 81), and which coordinates the plethora of daily tasks required to maintain an active rice paddy. Decisions about the timing of water use are particularly critical: in order to maximise the availability of water, each irrigation area would plant their crops-and so draw on the water-at different times. However, this would enable a build-up

${ }^{4}$ Some of the historical reasons for this compliance are discussed by Graham (1993). 
of pests, which would be able to move from a drying area to a newly-planted one. On the other hand, synchronising the watering and fallowing of paddies would deny pests a continuous food supply, but demand for water would be very uneven, as all farmers would need water at the same time, then none would need it. Through the temple system, subaks work together to strike a balance between water use and pest damage, and thus maximise the harvest (Schoenfelder, 2000, p. 38). This system has produced sustainable, high-yield and adaptive cropping over a long period of time.

Wet rice irrigation technology has been employed in Bali since at least the $9^{\text {th }}$ century CE, when the island was ruled by Indianized kings. Hillsides were terraced to create wet rice fields, and tunnels were constructed through the steep and highly dissected ridges (Scarborough et al., 2000, p. 80). By the $11^{\text {th }}$ century centralisation of power was increasing, but the island was invaded by the Javanese in the $13^{\text {th }}$ and $14^{\text {th }}$ centuries, and over the succeeding centuries, as Schoenfelder (2000) puts it, "the core region of southern Bali seems to have become increasingly ungovernable as a single entity" (p. 43). The large kingdoms were replaced by dozens of smaller independent and semiindependent principalities (Geertz, 1980, p. 19). These operated as largely non-instrumental "theatre states," which had an important symbolic role, but little involvement with the construction or management of the irrigation systems that provided rice in abundance to support them. This is perplexing, as the irrigation systems presented an opportunity for the regents to exercise control and increase their power and wealth, but Scarborough et al. (2000) have argued that as the population increased and along with it the amount of food to be produced, control over the irrigation systems that were fundamental to the society was relinquished to the evolving subak (p. 82). Because the Balinese regents did not-or were not able to-exercise greater control, and establish greater centralisation of population and resources, the society developed along lines that better matched the dispersed resource base within a tropical ecosystem. Schoenfelder (2000) argues that it was the emergence of pest and water stresses, as population grew and irrigation systems became larger and more complex, that provided the impetus for the organisation of subaks as self-organising networks of social groups, that could micro-manage local systems in a coordinated way, for optimum yields (p. 41). As a result, "On Bali, culture and agriculture have long prospered because of a sophistication about the landscape derived from evaluating ecological and economic relationships within the evolving engineered environment" (Scarborough et al., 2000, p. 90). The engineering of the landscape occurred slowly and incrementally over time, and the groups that lived and worked in that landscape were able to adapt to changes in the environment, because of their intimate knowledge of the landscape and capacity to share knowledge with neighbours. ${ }^{5}$

The system has also proven resilient: when the "green revolution" came to Bali in the late 1960s, farmers were encouraged to plant the new high-yielding rice varieties as quickly as possible, and traditional irrigation patterns were abandoned. Yields did indeed rise, but so did problems of water shortage and pest outbreaks. A similar challenge occurred when a large irrigation development project, funded by the Asian Development Bank, was launched in 1979. Local irrigation systems were restructured by irrigation engineers, but the new systems often neglected to consider the context of social relationships within which irrigation was managed. As a result, arguments broke out within subaks that had been merged; in some cases, subaks refused to use the new systems, opting instead to recreate the old canals. Between 1982 and 1985, the island experienced declines in both crop yields and cropped areas, as a result of the bureaucratic and engineering interventions. However, the work of anthropologist J. Stephen Lansing, amongst others, convinced the Indonesian government to encourage the restoration of the subak system. The water temples subsequently

${ }^{5}$ Lansing has proposed that the widespread use of a simple adaptive rule-“copy your neighbour's crop timing if your neighbour's rice yields are higher than yours" - created a system that was adaptive to change in the natural or built environment (Schoenfelder, 2000, p. 39). 
regained informal control over wet rice cropping on most of the island and by 1991 the traditional systems were once again in place (Lansing, 2008, pp. 111-125). This marked not only the end of the immediate problems of decline in cropping and yields, but also a return to a system that was both more sustainable and more socially-just, based on equity, cooperation and democratic values.

\section{LEARNING From The PAST}

What, then, can these historical narratives of the development of two highly-engineered irrigation landscapes offer to engineering students? Firstly, they begin to provide the "inventory of alternatives" that is one of the key social resources generated by historical scholarship. In a highlycited article published in Science in 1993, three scientists claimed that "Although there is considerably variation in detail, there is remarkable consistency in the history of resource exploitation: resources are inevitably overexploited, often to the point of collapse or extinction" (Ludwig, Hilborn, \& Walters, 1993, pp. 17, 36). The example of Balinese irrigation gives us a little more hope than this, showing that management of water resources can be sustained without overexploitation for a long period, if appropriate social structures, relationships and values are in place.

Secondly, both examples highlight the important problem of scale: the capacity for engineers to create systems - be they irrigation, communication, transport, power, or otherwise-on a massive scale has the potential for correspondingly far-reaching consequences. Thirdly, if these historical examples are extended, they demonstrate that engineering works that lead to undesirable social or ecological outcomes are not characteristic of any one time or place, or indeed political regime. For example, the ecological disasters precipitated by irrigation projects in California (Hundley, 2001; Reisner, 1986) occurred in a democratic, capitalist context very different to the command economy of Soviet Central Asia.

Contrasting the Balinese and Aral basin experiences, however, some important issues for sociallyjust and sustainable engineering begin to emerge. One relates to centralised power and decisionmaking. Where decisions about engineering interventions are made on the basis of abstract knowledge of local landscapes and relevant social structures, and make little provision for effective local involvement in management of engineered systems, they are unlikely to deliver sustainable and just solutions. If, on the other hand, local people with first-hand knowledge of the land and its social context are empowered to have meaningful input into decisions about the role of engineering in local problem-solving, the chances of a socially-just and sustainable engineering solution are surely greater. The issues here might be summarised as power, knowledge and proximity. They point to the inadequacy of traditional engineering practice in which a design brief is prepared in consultation with a client, but not necessarily those who will potentially use or live with the system or object to be produced. Another issue that students might be led to consider from comparison of these case studies is that of the potential advantages of incremental change to enable adaptation, or amelioration of emerging problems before they become major or irreversible.

Still, the key lesson to be learnt from historical interpretations of past engineering practices, such as those considered here, is that resource problems-which many engineering projects seek to address - are fundamentally "human problems that we have created at many times and in many places, under a variety of political, social and economic systems" (Ludwig et al., 1993, p. 36). The idea of engineering as delivery of technical solutions no longer stands up: engineers are working with complex "human-technology-environment systems" (Pahl-Wostl, 2002, p. 396), and as such, they must give as much consideration to the human elements of those systems as the technological and environmental components. 
The problem of a narrow, technical approach to problem-solving by engineers has arisen as engineering has increasingly come to be understood as a set of universal, transferable knowledge and practices, rather than a discipline that foregrounds context. History, as a stubbornly contextual discipline, can perhaps help to re-inject the required sense of the critical importance of social and ecological contexts for engineering design: varied contexts call for diverse approaches to problemsolving, which may well involve knowledge and techniques outside the scope of current mainstream notions of "engineering."

Of course there is an emerging technical literature on adaptive and participatory management, but in spite of these concepts now being decades old, they are still quite fluid, and may be insufficiently able to engage with multiple stakeholders (McLain \& Lee, 1996). Moreover, as Claudia Pahl-Wostl (2002) has put it, "major conceptual gaps exist regarding how to include the human dimension into integrated assessment models and processes" (p. 395). Furthermore, rarely can such technical works match the ability of historical narratives-stories about people-to engage interest, and facilitate deep understanding. Historical stories can graphically illustrate what is at stake in engineering projects that succeed or fail in effectively negotiating their social and ecological contexts to achieve socially-just and sustainable outcomes.

The examples chosen here are perhaps less successful in demonstrating how and why the stakes of engineering projects are often concealed by a narrow focus on technical elements. This was not an issue in the contextually-embedded, socially-responsive engineering practice seen in Bali, and the regime under which Soviet engineers operated was so oppressive that even had their education been less narrowly technical, to challenge the dominant engineering paradigm was likely to have involved life-threatening risks. What is needed are more examples from the twentieth century global north which highlight the role of engineering culture in reducing engineering questions to technical ones, and thus provoke students to think about what it would take as an engineer to challenge this culture from within. Also useful would be historical analyses that interrogate the significance of capitalist control of engineering systems, and the ways in which engineering systems have been shaped by profit motives at the expense of social justice and sustainability. ${ }^{6}$

\section{CONCLUSION}

Historical studies appear to have considerable potential in the education of engineers, offering interesting case studies for students to consider and reach conclusions about the importance of an engineering practice that gives due attention to social and ecological contexts, and aims to achieve social justice and ecological sustainability among its core outcomes. The two case studies we have chosen explore issues of relevance to students in any area of engineering, though they might be most germane, and thus have greatest appeal, to students intending to work in the areas of civil or environmental engineering, or in a developing world context. As issues of sustainability and social justice are just as critical, if perhaps not always so obvious, in the industrialised west, one challenge for historians and engineering educators together would be to locate a broad range of case studies, involving diverse engineering projects in multiple historical contexts, for use in engineering classrooms.

\footnotetext{
${ }^{6}$ See for example Jones (2013, pp. 160-161).
} 


\section{ACKNOWLEDGEMENTS}

We would like to thank the anonymous referees for their helpful comments. The research and writing of this paper was supported by Australian Learning and Teaching Council Grant CG10-1519 "Engineering Education for Social and Environmental Justice."

\section{REFERENCES}

Beder, S. (1998). The new engineer. Sydney, Australia: Macmillan.

Brookfield, H. (1999). Environmental damage: Distinguishing human from geophysical causes. Environmental Hazards , 1, 3-11. doi:10.3763/ehaz.1999.0102

Conlon, E. (2008). The new engineer: Between employability and social responsibility. European Journal of Engineering Education, 33(2), 151-159. doi:10.1080/03043790801996371

Cronon, W. (1992). A place for stories: Nature, history and narrative. Journal of American History, 78(4), 1347-1376. http://www.jstor.org/stable/2079346

Davis, N. Z. (1984). Interview. In H. Abelove (Ed.), Visions of history (pp. 114-5). Manchester, UK: Manchester University Press.

Dobson, A. (2003). Social justice and environmental sustainability: Ne'er the twain shall meet? In J. Agyeman, R. D. Bullard \& B. Evans, (Eds.), Just sustainabilities: Development in an unequal world (pp. 83-98). London, UK: Earthscan.

Geertz, C. (1980). Negara: The theatre state in nineteenth-century Bali. Princeton, NJ: Princeton University Press.

Geertz, H., \& Geertz, C. (1975). Kinship in Bali. Chicago, IL: University of Chicago Press.

Glantz, M. H., Rubinstein A. Z., \& Zonn, I. (1993). Tragedy in the Aral Sea basin: Looking back to plan ahead? Global Environmental Change, 3(2), 174-198. doi:10.1016/0959-3780(93)90005-6

Graham, L. (1993). The ghost of the executed engineer: Technology and the fall of the Soviet Union. Cambridge, MA: Harvard University Press.

Hundley, N., Jr. (2001). The great thirst: Californians and water-A history (Rev. ed.). Berkeley: University of California Press.

Irvine, S. (2003). Brundtland commission. In S. Krech, J. R. McNeill, \& C. Merchant, Encyclopedia of world environmental history: $A-G$ (pp. 172-173). London, UK: Routledge.

Jasanoff, S. (Ed.). (2004). States of knowledge: The co-production of science and the social order. New York, NY: Routledge.

Jasanoff, S., Markle, G., Peterson, J., \& Pinch, T. (Eds.). (2001). Handbook of science and technology studies (Rev. ed.). Thousand Oaks, CA: Sage.

Johnston, S., McGregor, H., \& Taylor, E. (2000). Practice-focused ethics in Australian engineering education. European Journal of Engineering Education, 25(4), 315-324. doi:10.1080/03043790050200359

Jones, C. F. (2013). Building more just energy infrastructure: Lessons from the past. Science as Culture, 22(2), 157-163. doi:10.1080/09505431.2013.786991

Kotlyakov, V. M. (1991). The Aral Sea basin: A critical environmental zone. Environment, 33(1), 4-9, 36. doi:10.1080/00139157.1991.9931365

Langhelle, 0. (2000). Sustainable development and social justice: Expanding the Rawlsian framework of global justice. Environmental Values, 9(3), 295-323. http://www.jstor.org/stable/30301747

Lansing, J. S. (2008). Priests and programmers: Technologies of power in the engineered landscape of Bali. Princeton, NJ: Princeton University Press.

Lewis, R. A. (1962). The irrigation potential of Soviet Central Asia. Annals of the Association of American Geographers, 52(1), 99-114. http://www.jstor.org/stable/2561500

Ludwig, D., Hilborn, R., \& Walters, C. (1993, 2 April). Uncertainty, resource exploitation, and conservation: Lessons from history. Science, $260,17,36$. doi:10.1126/science.260.5104.17 
McLain, R. J., \& Lee, R. G. (1996). Adaptive management: Promises and pitfalls. Environmental Management, 20(4), 437-448. doi:10.1007/BF01474647

Micklin, P. P. (1992). The Aral crisis: Introduction to the special issue. Post-Soviet Geography, 33(5), 269-282. doi:10.1080/10605851.1992.10640900

Nieusma, D. (2004). Alternative design scholarship: Working toward appropriate design. Design Issues, 20(3), 13-24. doi:10.1162/0747936041423280

Nieusma, D., \& Riley, D. (2010). Designs on development: Engineering, globalization, and social justice. Engineering Studies, 2(1), 29-59. doi:10.1080/19378621003604748

O'Hara, S. L., \& Hannan, T. (1999). Irrigation and water management in Turkmenistan: Past systems, present problems and future scenarios. Europe-Asia Studies, 51(1), 21-41. doi:10.1080/09668139999100

Pahl-Wostl, C. (2002). Towards sustainability in the water sector: The importance of human actors and processes of social learning. Aquatic Sciences: Research Across Boundaries, 64(4), 394-411. doi:10.1007/PL00012594

Reisner, M. (1986). Cadillac desert: The American West and its disappearing water. New York, NY: Penguin.

Riley, D. (2008). Engineering and social justice. San-Rafael, CA: Morgan \& Claypool.

Scarborough, V. L., Schoenfelder, J. W., \& Lansing, J. S. (2000). Ancient water management and landscape transformation at Sebatu, Bali. Indo-Pacific Prehistory Association Bulletin, 20, 79-92. http://iournals.lib.washington.edu/index.php/BIPPA/article/view/11744/10373

Schoenfelder, J. W. (2000). The co-evolution of agricultural and sociopolitical systems in Bali. Indo-Pacific Prehistory Association Bulletin, 20, 35-46. http://journals.lib.washington.edu/index.php/BIPPA/article /view/11740/10369

Thomas, V., \& Ahmad, M. (2009). A historical perspective on the Mirab system: A case study of the Jangharoq Canal, Baghlan. Kabul, Afghanistan: Afghanistan Research and Evaluation Unit.

Tosh, J. (with Lang, S.). (2006). The pursuit of history: Aims, methods, and new directions in the study of modern history (4th ed.). Harlow, UK: Longman.

Weiner, D. H. (2003). Asia, Central. In S. Krech, J. R. McNeill, \& C. Merchant, Encyclopedia of world environmental history: $A-G$ (pp. 69-73). London, UK: Routledge.

White, H. (1973). Metahistory: The historical imagination in nineteenth-century Europe. Baltimore, MD: John Hopkins University Press.

World Commission on Environment and Development. (1987). Our Common Future. Oxford, UK: Oxford University Press. 